\title{
LESIONS OF THE LID MARGINS CAUSED BY ECTOPARASITES IN INDIA*
}

BY

\author{
F. C. RODGER AND H. U. FAROOQI
}

From the Institute of Ophthalmology and Department of Zoology, Muslim University, Aligarh, India

INFESTATION with Anoplura, where the nits of lice are found attached to the eyelashes, is a phenomenon which has been frequently reported during the past 70 years (Goldenberg, 1887, and many others). Sporadic reports have also appeared of a persistent blepharitis resulting from such infestation (e.g. Boase, 1945), and this is probably more common than is generally known. The louse concerned is said to be the head louse, for it is believed that the body louse is never found on the lids or lashes (Duke-Elder, 1952). These two ectoparasites are of the same species, are identical morphologically, and may overlap in size and habitat; in fact, there is a closer similarity between these lice than there is between most varieties of Homo sapiens. The body louse may sometimes be found on the lid margins, and the nits are indistinguishable.

The presence on or near the head region of the pubic (crab) louse is even more surprising than that of the body louse, but this paradox has long been recognized, and was first described by Jullien (1891a, b; 1892a, b). Friedman and Wright (1934) suggested that it was transmitted by hand, presumably in the form of the nits. Boase $(1945,1947)$ gives the most recent account of the blepharo-conjunctivitis which occurs in some cases of ectoparasitism, especially with the crab louse. Chandler (1955) described a patient who was infested from eyebrows to ankles. Sabata (1932) described a severe conjunctivitis associated with this variety of louse.

As these ectoparasites are very common in India we have been able to examine several cases where involvement of the lid margins had produced a well-developed inflammation.

Whether the hair follicle mite should be considered a saprophyte or a true parasite of man has not been decided. Its cosmopolitan distribution and high incidence suggest the former, although Ayres and Anderson (1932) claim that it causes a dry scaly dermatitis in man. Several writers (e.g. Fuss, 1933, 1935) have claimed that it can cause blepharitis, but this question first posed by Raehlman (1898) is still unsolved. Gmeiner (1908) found it in 97 healthy subjects out of a hundred in a random sample, which suggests that pathological lesions may be due to another variety of parasite. In Uttar Pradesh we found the hair follicle mite an infrequent but definite cause

* Received for publication December 22, 1958. 
of blepharo-conjunctivitis in man, and we feel that it is not without significance that the same species causes mange in dogs, which are present in large numbers in this Province. Passage through one of the carnivora may alter the secretions of the mite, or there may be two different varieties, morphologically identical as in the case of lice. In either event the operative factor would be the relation to dog.

\section{Ectoparasitic Lesions of the Eyelids}

(1) Lice.-Three distinct species of the order Anoplura have been found on the eyelids and eyelashes: Pediculus humanus capitis, Pediculus humanus corporis, and Phthirus pubis. The first breeds on the hair of the head and the second in the seams and linings of the clothing, and to a lesser extent in the hair of the chest and axillae. The third is essentially a dweller in the pubic and peri-anal regions.

(a) Head and Body Lice.-Although these two varieties closely resemble each other, they can usually be differentiated by their size. P. capitis females are seldom more than $2 \mathrm{~mm}$. in length, and $P$. corporis seldom less. The former is further distinguished by the presence to a varying extent of a dark pigmented margin which the body louse is believed to lack.

Infants and children are especially affected by these two ectoparasites, and when the eyelids are invaded the scratching which results is almost entirely responsible for the unfortunate consequences. The parasites have a liking for the fine hairs of the eyebrows, and near this site excoriation of the skin by the finger nails often leads to the formation of an abscess. Adults in developing areas of the East are more likely to neglect itching in a child than in themselves, which is a pity as the condition is so readily cured. The high re-infection rate, however, is discouraging even to the most careful parent. The inflammation and hypersensitivity of the lid margins is not as great as with the crab louse and the hair follicle mite.

(b) Crab Louse.-This can be readily distinguished from the other two by its shape, although its physiology is similar to that of the other lice. The females measure about $2 \mathrm{~mm}$. in length, the males slightly less. Although its normal habitat is the pubic and anal region, we have found crab lice not only clinging to the eyelashes, but breeding there. The nits are larger than those of the head and body lice, and can more readily be spotted by the naked eye. The lesions it produces are more severe than those produced by head and body lice because of its tough claws and sharp jaws.

Irritation and pruritus, involving the conjunctiva as well as the lids, are intense and the subject scratches at his eyes in desperation. Secondary infection affects the conjunctiva, the cilia becoming matted together with muco-pus mixed with nits. The appearance then suggests a complicated trachoma. Abscesses of the soft skin of the lid, especially at the temporal side, are common, and may be one explanation for the high incidence of such abscesses reported by other workers in India (Singh and Grover, 1958). The 
villagers get rid of the scourge by rubbing the eyelids with wood ash; this removes the lice, but also leads to loss of the eyelashes, the lid margins and conjunctiva being left swollen and inflamed, and vulnerable to other infections (Fig. 1).

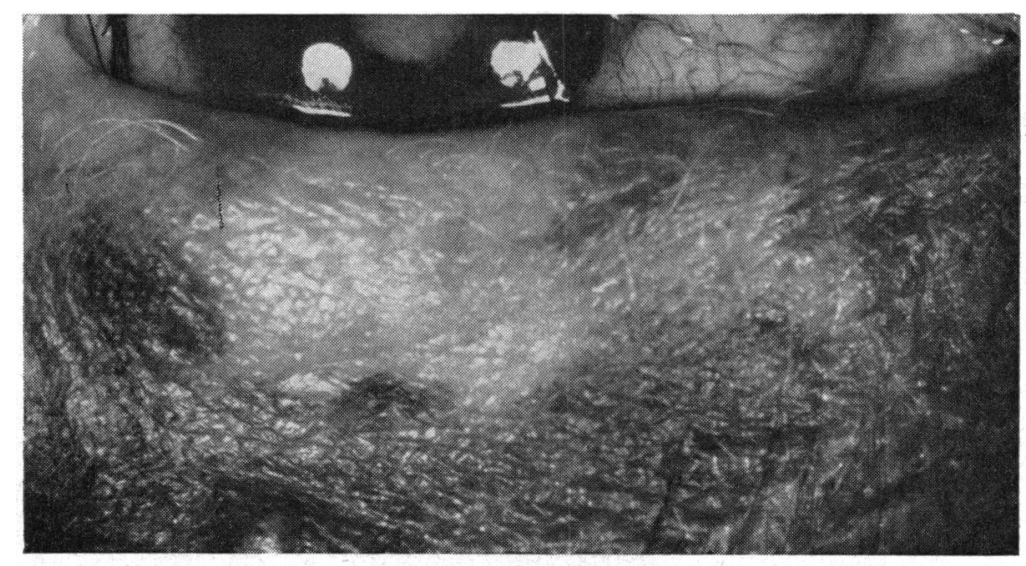

FIG. 1.-Swollen erythematous lid and madarosis after scrubbing with wood ash to eliminate crab lice.

This condition also resembles that of trachoma and is frequently confused with it. The idea of using wood ash to remove lice was perhaps derived from the knowledge that poultry get rid of lice in this manner.

(2) Follicular Mites.-These belong to the family Demodecidae, genus Demodex, and are parasites of the sebaceous glands and hair follicles in man and in certain carnivora. They are too small to be seen with the naked eye.

Demodex folliculorum, the only species apparently found in man, is an elongated, vermiform, cylindrical mite with four pairs of short stumpy legs, three of which are jointed, a short median sucking capitulum and a long, tapering, transversely-striated abdomen. The females are larger than the males, averaging up to $400 \times 40 \mu$. They are characterized by a long, slit-like vulva at the base of the abdominal venter. The males are comparatively slender, and do not exceed $300 \mu$ in length. These parasites, when they invade the lids, burrow head down into the follicles of the cilia and sebaceous or Meibomian glands, where they often group together in clusters, forming black "pustules" at the lid margins. The eggs laid in the burrows hatch into hexapod larvae which in turn moult into octapod nymphs and develop (after two more moults) into adults. In addition to hiding in the hair follicles some of them can usually be found free on the lid margin or attached to the cilia (Fig. 2, opposite). Inflammation of the Meibomian glands and lid margins follows; as in all ectoparasitic infestation, the damage is due partly to the activity of the parasite and partly to the host himself scratching the part 


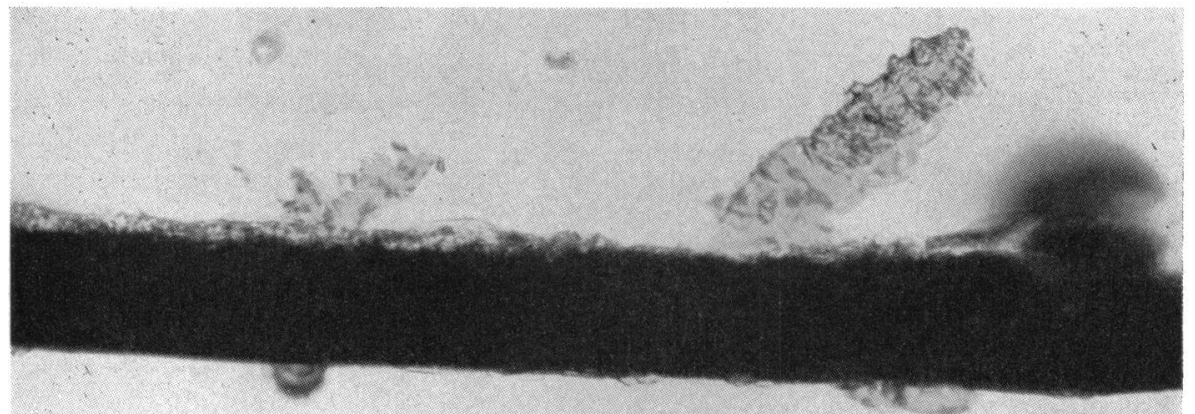

Fig. 2.-Demodex folliculorum Simon on a human eyelash in a case of chronic unresponsive blepharo-conjunctivitis

invaded. Even after the mites have been eliminated a dry scaly, chronic blepharo-conjunctivitis persists for long periods, and can be as irritating as the parasite itself, probably because of the development of hypersensitivity. Cases of severe unresponsive blepharo-conjunctivitis in persons of a type likely to be infested should always be examined for mites, especially if the patient has been in contact with dogs from which they may have come either directly or in the finger nails as nymphs.

\section{Summary}

(1) A high incidence of follicular mites and lice among Indian peasantfarmers in Uttar Pradesh is described.

(2) Head, body, and crab lice sometimes breed on the eyelashes, giving rise to a chronic blepharitis, the most severe lesions being those caused by the crab louse.

(3) Secondary infection prolongs the condition and conjunctivitis may develop.

(4) Follicular mites, which also infest the dog, may invade the eyelids of man and cause inflammation of the Meibomian glands and chronic hypersensitive blepharo-conjunctivitis as well as the expected acute blepharitis.

(5) Uncontrolled scratching is liable to give rise to lid abscesses. In severe cases, especially with crab lice, the eyelashes may be lost, and the lids may become inflamed through rubbing wood ash vigorously into the roots of the cilia to remove the lice.

(6) Where the lids are matted with nits and secondary infection exists, or when the lashes have been rubbed off leaving swollen erythematous lids, the condition is frequently confused with trachoma.

The authors are grateful for laboratory facilities provided by Prof. B. R. Shukla, Director of the Institute of Ophthalmology, and Prof. M. B. Mirza, Head of the Department of Zoology, Aligarh Muslim University. 


\section{REFERENCES}

Ayres, S., and ANDerson, N. P. (1932). Arch. Derm. Syph. (Chicago), $25,89$.

BOASE, A. J. (1945). E. Afr. med. J., 22, 271.

(1947). Ibid., 24, 363.

Chandler, A. C. (1955). "Introduction to Parasitology", 9th ed., p. 605. Wiley, New York. DUKE-ELDER, S. (1952). " "Text-book of Ophthalmology", vol. 5, p. 4926. Kimpton, London. Friedman, R., and Wright, C. S. (1934). Arch. Ophthal. (Chicago), 11, 995.

Fuss, F. (1933). Ann. Derm. Syph., 7 sér., 4, 1053. (1935). Ibid., 7 sér., 6, 326.

GMEINER, F. (1908). Arch. Derm. Syph. (Wien), 92, 25.

GOLDENBERG, H. (1887). Berl. klin. Wschr., 24, 866.

Jullien, L. (1891a). Ann. Oculist. (Paris), 106, 450.

(1891b). Bull. Soc. franc. Derm. Syph., 2, 457.

(1892a). Ann. Derm. Syph., 3 sér., 3, 158.

(1892b). Gaz. Hôp. Paris, 65, 43.

Raehlman, E. (1898). Klin. Mbl. Augenheilk., 36, 33.

SABATA, J. (1932). Oft. Sbornik., 7, 282.

SingH, S., and GROVER, A. D. (1958). Amer.J. Ophthal., 46, 77. 